Article publié par le Laboratoire de Construction en Béton de l'EPFL

\begin{tabular}{|l|l|}
\hline Title: & $\begin{array}{l}\text { Shear strength of concrete members without transverse reinforcement: A } \\
\text { mechanical approach to consistently account for size and strain effects }\end{array}$ \\
\hline Authors: & Fernández Ruiz M., Muttoni A., Sagaseta J. \\
\hline Published in: & Engineering structures \\
\hline DOI & $10.1016 /$ j.engstruct.2015.05.007 \\
\hline Pages: & pp. 360-372 \\
\hline Country: & UK \\
\hline Year of publication: & 2015 \\
\hline Type of publication: & Peer reviewed journal article \\
\hline
\end{tabular}

Please quote as:

Fernández Ruiz M., Muttoni A., Sagaseta J., Shear strength of concrete members without transverse reinforcement: A mechanical approach to consistently account for size and strain effects, Engineering structures, UK, 2015, pp. 360-372. 


\title{
Shear strength of concrete members without transverse reinforcement: A mechanical approach to consistently account for size and strain effects
}

\author{
M. Fernández Ruiz ${ }^{a, *}$, A. Muttoni ${ }^{a}$, J. Sagaseta ${ }^{\mathrm{b}}$ \\ a École Polytechnique Fédérale de Lausanne, Station 18, CH-1015 Lausanne, Switzerland \\ ${ }^{\mathrm{b}}$ University of Surrey, Guildford, Surrey GU2 7XH, United Kingdom
}

\section{A R T I C L E I N F O}

\section{Article history:}

Received 19 February 2015

Revised 3 May 2015

Accepted 7 May 2015

\section{Keywords:}

Concrete structures

Shear strength

Aggregate interlock

Residual tensile strength of concrete

Dowel action

Arching action

Critical Shear Crack Theory

Size effect

Strain effect

\begin{abstract}
A B S T R A C T
Many theories and empirical formulae have been proposed to estimate the shear strength of reinforced concrete members without transverse reinforcement. It can be noted that these approaches differ not only in the resulting design expressions, but also on the governing parameters and on the interpretation of the failure mechanisms and governing shear-transfer actions. Also, no general consensus is yet available on the role that size and strain effects exhibit on the shear strength and how should they be accounted. This paper reviews the various potential shear-transfer actions in reinforced concrete beams with rectangular cross-section and discusses on their role, governing parameters and the influences that the size and level of deformation may exhibit on them. This is performed by means of an analytical integration of the stresses developed at the critical shear crack and accounting for the member kinematics. The results according to this analysis are discussed, leading to a number of conclusions. Finally, the resulting shear strength criteria are compared and related to the Critical Shear Crack Theory. This comparison shows the latter to be physically consistent, accounting for the governing mechanical parameters and leading to a smooth transition between limit analysis and Linear Elastic Fracture Mechanics in agreement to the size-effect law provided by Bažant et al.
\end{abstract}

(c) 2015 Elsevier Ltd. All rights reserved.

\section{Introduction}

Design for shear of one- and two-way slabs without transverse reinforcement has been a topic where significant efforts have been devoted in the past. For beams and girders with stirrups, consistent equilibrium-based models as strut-and-tie models or stress fields can be applied [1]. However, with reference to the shear strength of beams and slabs without transverse reinforcement, no general agreement on the parameters and phenomena governing shear strength is yet found in the scientific community. This lack of agreement is also reflected in codes of practice, whose provisions for shear design are often based on empirical formulas $[2,3]$. Some approaches based on mechanical models consider a given shear transfer action as governing, neglecting the influence of the others. For instance, for one-way slabs without transverse reinforcement, shear carried by the compression chord is identified as the most significant parameter influencing the shear strength by Zararis [4]. On the contrary, aggregate interlocking can be considered as the governing shear transfer action explaining shear strength according to the compression field theory and its

\footnotetext{
* Corresponding author.

E-mail address: miguel.fernandezruiz@epfl.ch (M. Fernández Ruiz).
}

derivatives [5,6]. Also, Yang [7] acknowledges the role of aggregate interlock, whose failure is triggered by the development of a delamination crack at the level of the flexural reinforcement. Other approaches deal with the problem of shear strength in beams without transverse reinforcement on the basis of the tensile strength after cracking (including the presence of fibres in the cement matrix [8]) or based on fracture mechanics concepts $[9,10]$. Some interesting research lines have also been developed based on the upper-bound theorem of limit analysis with some modifications accounting for the presence of concrete cracking $[11,12]$. Finally, other approaches account for various potential shear-transfer actions. This is for instance the approach of Tue et al. [13] and Marí et al. [14] (where the role of the compression chord is nevertheless normally dominant) or the Critical Shear Crack Theory $[15,16]$ (where the development of a critical shear crack limits the capacity of the shear-transfer actions). It is noticeable that, although different models account for different governing shear-carrying actions and for the strain and size effects in different manners, the final design expressions account for similar parameters with similar influences and, in most cases, fit in a similar manner when compared to available datasets.

An attempt to understand the role of the various potential shear transfer actions has recently been presented by Campana et al. 


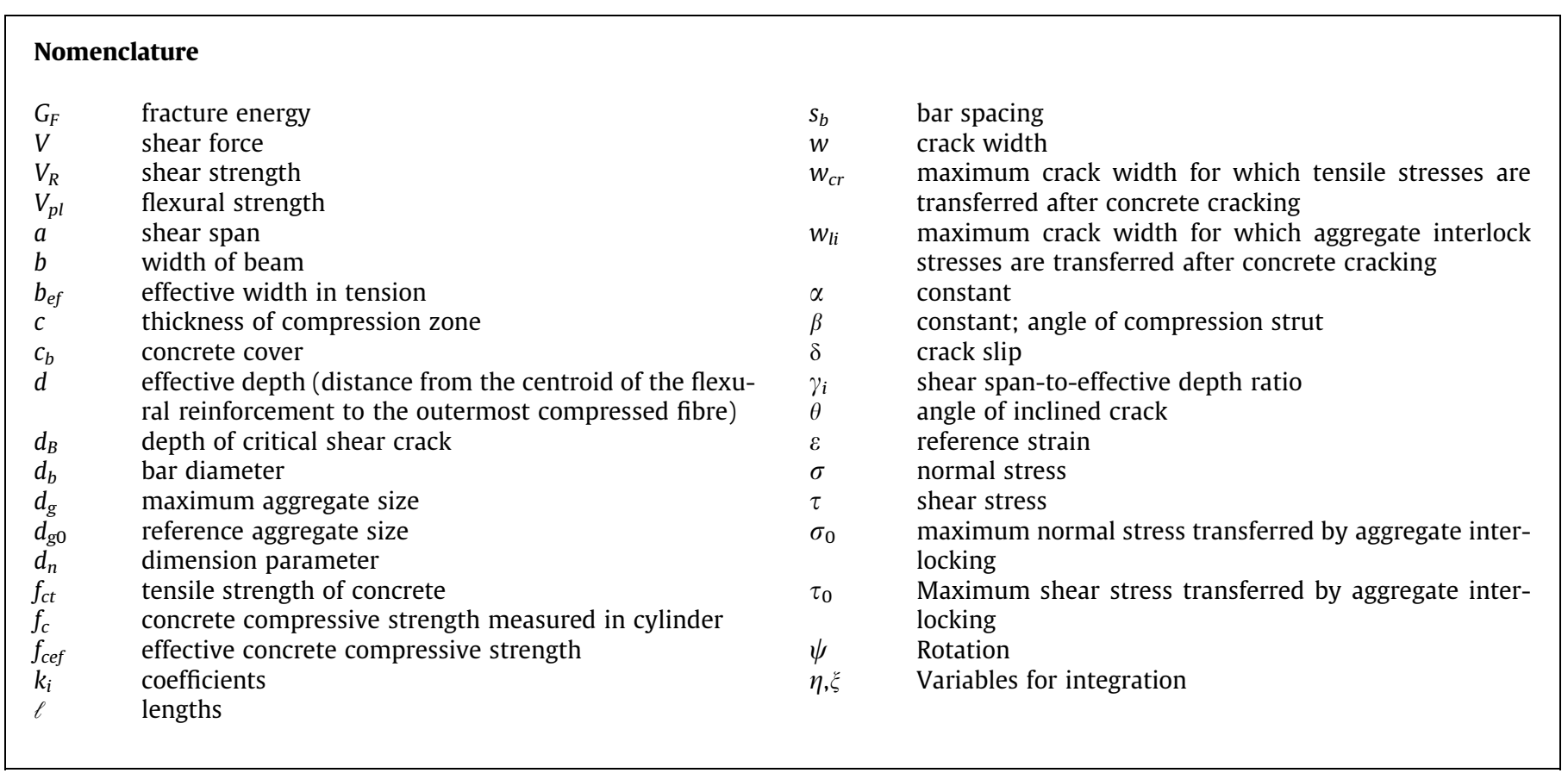

[17]. This investigation showed that different crack patterns may develop in similar reinforced concrete members and that their associated kinematics at failure (relative displacement of the lips of the critical shear crack) may also be very different. This holds true even for constant mechanical and geometrical parameters. Accounting for measured shapes and kinematics obtained by specific testing and by using a number of advanced constitutive models for aggregate interlock, residual tensile strength, doweling action and stirrup contribution, the contribution of each shear-transfer action to the total strength was estimated numerically. It was found that the governing shear transfer actions may be very different from one member to another. This dependency was mostly governed by the cracking pattern and its associated kinematics at failure, despite the fact that the total shear strength (sum of the various shear transfer actions) may be similar.

Other than the role attributed to the shear-transfer actions, different considerations are usually performed on the influence that size and strain effects have on shear strength. The size effect is defined as the reduction on the unitary (normalized) shear strength for geometrically identical specimens but with increasing size, refer to Fig. 1a. As stated by Bažant et al. [9,10], this reduction should follow a size-effect law, with a transition between a yield criterion for small sizes (without any size effect) and the behaviour predicted by Linear Elastic Fracture Mechanics (LEFM) for large sizes (strength reduction governed by $d^{-0.5}$ ). In addition, it has also been experimentally observed that specimens are sensitive to a strain effect $[6,15]$, with decreasing unitary shear strength for geometrically identical specimens but subjected to higher levels of deformation (Fig. 1b). In many cases, both effects are considered by means of empirical coefficients, by introducing a size-effect factor (depending on the depth $[9,10]$ or on shear span length $[4,14]$ ) and by relating the shear strength to the level of deformation (for instance as a function of the flexural reinforcement ratio or axial load $[13,3])$. Some design codes, however, neglect these aspects, at least in their most simplified design formulations [2].

In this paper, the contribution of the various shear-transfer actions to the shear strength and how they are influenced by the size and level of deformation of the member is investigated. This is performed by means of an analytical approach, accounting for their activation based on the shape of the shear crack and its kinematics and by using some fundamental constitutive models providing the stresses along the critical shear crack. By integration of the stresses at the critical shear crack, the contribution of each shear-transfer action is determined as well as its governing parameters. This allows obtaining eventually a failure criterion for shear design as well as to investigate on the influence of size and strain effects on the shear response. The results show that the contributions of all shear-transfer actions decrease for increasing openings of the critical shear crack and that their decay follows a similar trend. These results are finally related to the failure criterion proposed by the Critical Shear Crack Theory [15]. The works of this paper allow justifying on a rational basis its failure criterion (shape and influence of the various mechanical parameters considered by the theory). This criterion is observed to be consistent with the integration of stresses performed for the various critical shear crack shapes and kinematics investigated, thus validating the fundamental hypotheses of this theory. In addition, it is also shown that the theory is consistent with the strain effects and particularly with the size-effect law, providing naturally (without the need of considering any specific parameter) a smooth transition between a yield criterion and LEFM depending on the size of the member.

\section{Shear-transfer actions in RC}

After cracking due to bending, shear can be transferred in reinforced concrete members by a number of potential actions, whose activation depends much on the shape and kinematics of the critical crack leading to failure $[17,15]$. A summary of these actions is presented below (refer to Fig. 2):

- Cantilever action (Fig. 2a). The possibility of transferring shear by means of the concrete in between two flexural cracks (acting as a cantilever beam or "tooth" linking the tension and compression chords) was already observed by Kani [18]. At the location of the crack, shear is carried by the inclined compression chord. The strength of this action is limited by the development of the vertical flexural crack into a quasi-horizontal crack, which disables the capacity of the tension tie of the tooth [15]. 
(a)

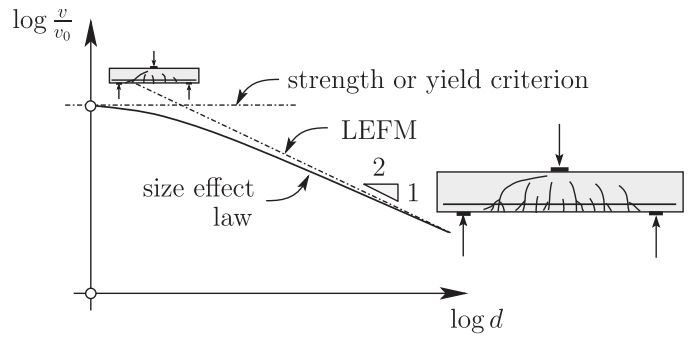

(b)

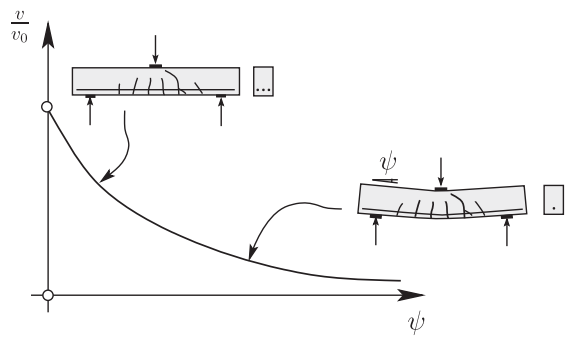

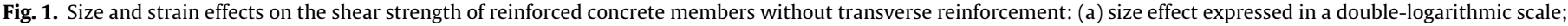
and (b) strain effect expressed in terms of member deformation.

(a)

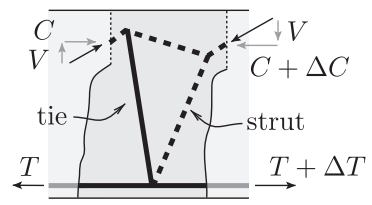

(c)

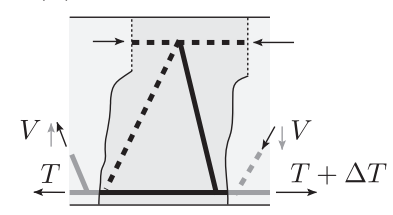

(e)

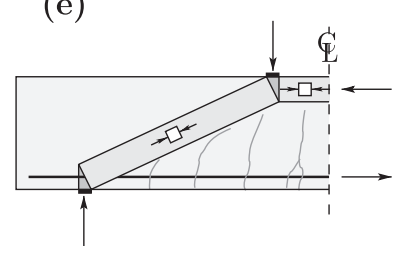

(b)

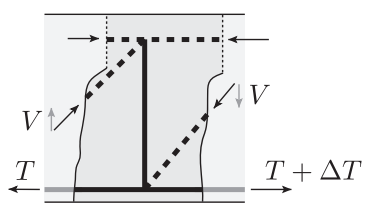

(d)



(f)

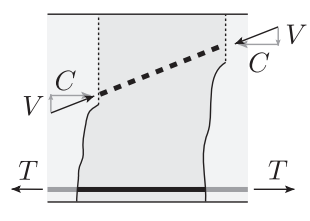

Fig. 2. Shear-transfer actions: (a) cantilever action; (b) aggregate interlock; (c) dowel action; (d) residual tensile strength of concrete; and (e-f) arching action.

- Aggregate interlock (Fig. 2b). Aggregate interlock was also early acknowledged as a potentially governing shear transfer action [19-24]. In a concrete crack, aggregate interlocking stresses develop when the aggregates at one side of the crack contact the cement paste in the other. Thus, depending on the crack opening $(w)$ and relative slip of the crack $(\delta)$, see Fig. 3a, normal and tangential stresses develop, Fig. 3b. The strength of this action is mostly limited by the opening of the cracks, by the roughness of the contact surface and by the level of slip $(\delta)$ between the lips of the crack. It should be noted that the

roughness of the crack is influenced by the aggregate size (micro-roughness) but also by the actual shape of the crack (crack undulations defining a meso-roughness and changes in the direction of the crack defining a macro-roughness).

- Doweling action (Fig. 2c). The longitudinal bars of a reinforced member also have the possibility to transfer shear forces acting as dowels between the lips of a crack [25-29]. This action has shown to be efficient in regions were concrete cannot develop spalling cracks. This is for instance the case of short-span beams (where the critical shear crack develops near the bearing plate, thus preventing spalling cracks to appear) or for members with transverse reinforcement $[30,17]$. Also, when the critical shear crack develops through the compression reinforcement (where no spalling can occur near the loading plate), dowelling action becomes very efficient (as for the integrity reinforcement [31]). However, when spalling cracks can develop parallel to the bending reinforcement (Fig. 2c) as for slender beams without transverse reinforcement, this action is significantly decreased, and even considered as negligible by many researchers $[29,4,15,28]$.

- Residual tensile strength of concrete (Fig. 2d). After cracking, concrete still has the capacity to transfer some level of tensile stresses, allowing tension ties to develop through the cracks. These stresses develop at the fracture process zone of the crack (near its tip) and soften for increasing openings of the crack width [32] (the concrete has eventually no capacity to carry any stress for crack openings of a quite limited width, of about $0.2 \mathrm{~mm}[33])$.

- Arching action (Fig. 2e and f). The four previous shear carrying actions (Fig. 2a-d) allow carrying shear in a member keeping constant the lever arm between the compression and tension chords. Thus, the force in the tension reinforcement varies accordingly to the bending moments of the beam. Due to this reason, such actions can be referred to as beam shear-carrying actions. However, shear can also be carried by assuming a constant force in the flexural reinforcement, which leads to an (a)

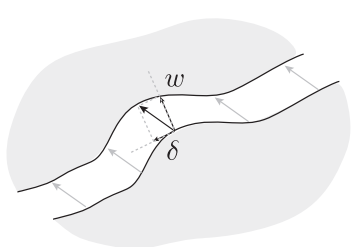

(b)

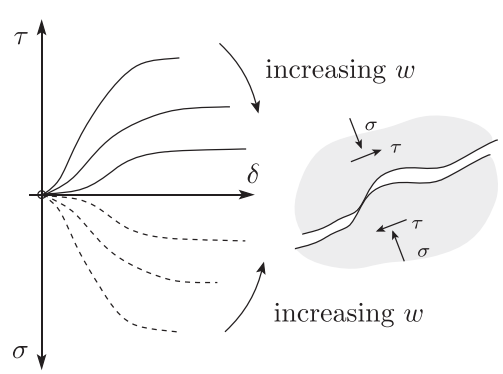

Fig. 3. Aggregate interlock: (a) kinematics of a shear crack with relative components of opening ( $w$ ) and slip ( $\delta$ ); and (b) contact stresses. 
inclined compression strut carrying shear as shown in Fig. 2e. This possibility corresponds in fact to a plasticity-based stress field in concrete without tensile strength as originally proposed by Drucker in 1961 [34]. Developing the full plastic strength on the basis of such stress field was not found possible for slender beams without transverse reinforcement $[18,15]$ as flexural cracks may potentially develop across the theoretical compression strut, limiting its strength. However, for compact (short-span) members, the results obtained according to the arching action are in agreement to observed test results $[35,36]$.

The influence of slenderness on the governing shear-carrying actions is presented in Fig. 4 with the help of the "Kani's valley". The arching action is governing for deep beams (beams with low shear span (a)-to-effective depth $(d)$ ratios $\gamma=a / d<\gamma_{1}$ in Fig. 4) and the shear that can be carried at failure $\left(V_{R}\right)$ corresponds to that of the plastic strength $\left(V_{p l}\right.$, governed by yielding of the flexural reinforcement and crushing of the concrete zone, according to Fig. 2e). This is due to the fact that for low slenderness, flexural cracks do not penetrate within the compression strut [15]. For larger slenderness $\left(\gamma_{1}<\gamma<\gamma_{2}\right)$ cracks may partly penetrate within the strut. As a consequence, the plastic solution overestimates the actual strength [18] (as the strength of the compression strut is limited by the transfer of forces across the critical shear crack and the compression strut develops with an elbow-shaped form as shown in Fig. 4a [15]). This region (left-hand side of the Kani's valley) can be investigated by using stress fields accounting for the influence of cracking on the strength of a compression field [5] (compression fields experiencing a reduction of the strength for transverse strains (strain effect) but no size effect, refer to $[37,38])$. For larger values of the slenderness $\left(\gamma>\gamma_{2}\right)$ the arching actions starts to develop in combination with the various beam shear-transfer actions (refer to the strut-and-tie model of Fig. 4), that become dominant thereafter. The ratio between the shear strength and the plastic strength increases in this case and gives rise to the characteristic shape of the right-hand side of the Kani's valley shown in Fig. 4 [18], where for very high values of the slenderness, the members fail again in bending (the beam shear-carrying actions offering sufficient shear strength). In this paper, the behaviour of slender members $\left(\gamma>\gamma_{2}\right)$ will be examined.

\section{Contributions of the shear-transfer actions in slender beams}

For slender members, the shape of the critical shear crack can be characterized according to Fig. $5 \mathrm{a}$ that is assumed to be composed of three parts (the actual shape of this crack being subjected to some level of scatter [17,39]): a quasi-vertical part (named A in Fig. 5a, developing at an angle $\theta_{A}$ ), a quasi-horizontal part (named $B$ in Fig. 5a, developing at an angle $\theta_{B}$ ) and a delamination crack (named $\mathrm{C}$ in Fig. 5a). The associated length of the former parts $\left(\ell_{B}\right.$ and $\left.\ell_{A}\right)$ can vary. In most cases, the quasi-vertical part $(A)$ has a bending origin

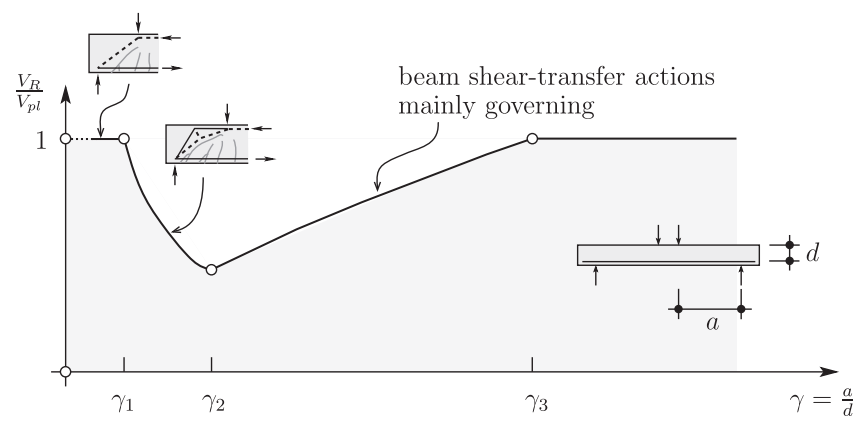

Fig. 4. Kani's valley: governing shear transfer actions as a function of shear slenderness. and extends approximately up to the neutral axis (or to the fibre where the tensile strength of concrete in bending is found), although diagonal cracks (associated to limited lengths of $\ell_{A}$ ) are also possible. The kinematics of such crack is presented in Fig. 5b, characterized by a centre of rotations located near the tip of the crack (in agreement to the test measurements presented in [17]). With respect to crack $B$, its origin can be related to the tensile stresses developing at that region due to the beam shear-carrying actions (refer to the quasi-vertical ties in Fig. 2a and d).

This crack shape (points A and B) and associated kinematics requires the development of a delamination crack at the level of the flexural reinforcement (Fig. 5a-b). This is justified by the vertical component of the displacement along the reinforcement shown in Fig. 5e which occurs for an inclined crack type A and when the quasi-horizontal crack type B develops. Along this crack, bond is not possible and the strain remains constant in the reinforcement (Fig. 5c), which increases the opening of the critical shear crack with respect to a bending-based prediction of its opening [7]. Thus, the rotation can be calculated on the basis of the deformation of the reinforcement at this crack as:

$\psi=\frac{w_{l}}{d_{B}}=\varepsilon_{s} \frac{\ell_{c}}{d_{B}}$

With respect to the potential shear transfer actions, other than the contribution along the shear crack ( $V_{C S C}$ in Fig. $5 d$ ) due to aggregate interlock and residual tensile strength, doweling action $\left(V_{D A}\right.$ in Fig. $\left.5 d\right)$ and the contribution of the compression chord $\left(V_{C C}\right.$ in Fig. $5 d$ ) can also be acknowledged. It is interesting to note that the kinematics (Fig. 5b) is governing the relative displacements of the lips of the crack. In the top part, this leads to a pure opening but no crack sliding (assuming that the shortening of the compression chord can be neglected, Fig. 5f) whereas in the middle part (length $\ell_{A}$, Fig. $5 \mathrm{~g}$ ), it is associated to variable opening and constant sliding along the crack.

\subsection{Contribution of the top part of the critical shear crack}

As previously introduced, the top part of the critical shear crack is subjected only to an opening of the crack. Its response is characterized thus by mode I in fracture and is then governed by the residual tensile strength of concrete (the interaction with potential shear stresses will be neglected). The force that can be transferred through the crack due to this contribution (Fig. 2d) can be calculated for a given tension softening behaviour. In the following, a simplified constant decay of the tensile strength with respect to the opening of the crack (linear law) will be assumed for simplicity reasons (Fig. 6a):

$\sigma=\left\{\begin{array}{cc}f_{c t}\left(1-\frac{w}{w_{c r}}\right) & 0 \leqslant w \leqslant w_{c r} \\ 0 & w>w_{c r}\end{array}\right.$

where the area below the crack-stress curve is equal to the fracture energy $G_{F}$. The integration of the shear contribution can however be generalised to any other tension softening law considered. The normal stresses developing at the crack can be calculated on the basis of the crack kinematics (Fig. 6b), determining a shear strength equal to:

$V_{C S C, B}=\int_{\eta=0}^{\ell_{B}} \sigma \cdot b \cdot \cos \theta_{B} \cdot d \eta=b \cos \theta_{B} \cdot \int_{\eta=0}^{\ell_{B}} \sigma \cdot d \eta$

where $\sigma$ refers to the normal stress to the crack, $b$ to the width of the member (considered constant), $\theta_{B}$ to the angle of the crack with respect to the beam axis and $\eta$ is the integration variable (Fig. 6b). With respect to the crack opening $(w)$, it can be obtained for the given kinematics by relating it to the rotation of the critical shear $\operatorname{crack}(\psi)$ developed at its centre of rotation (Fig. $6 \mathrm{~b}$ ): 


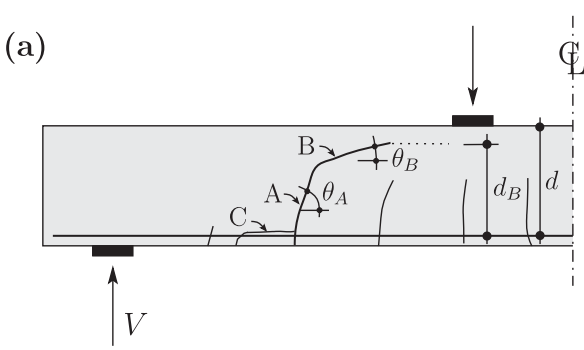

(d)

(b)
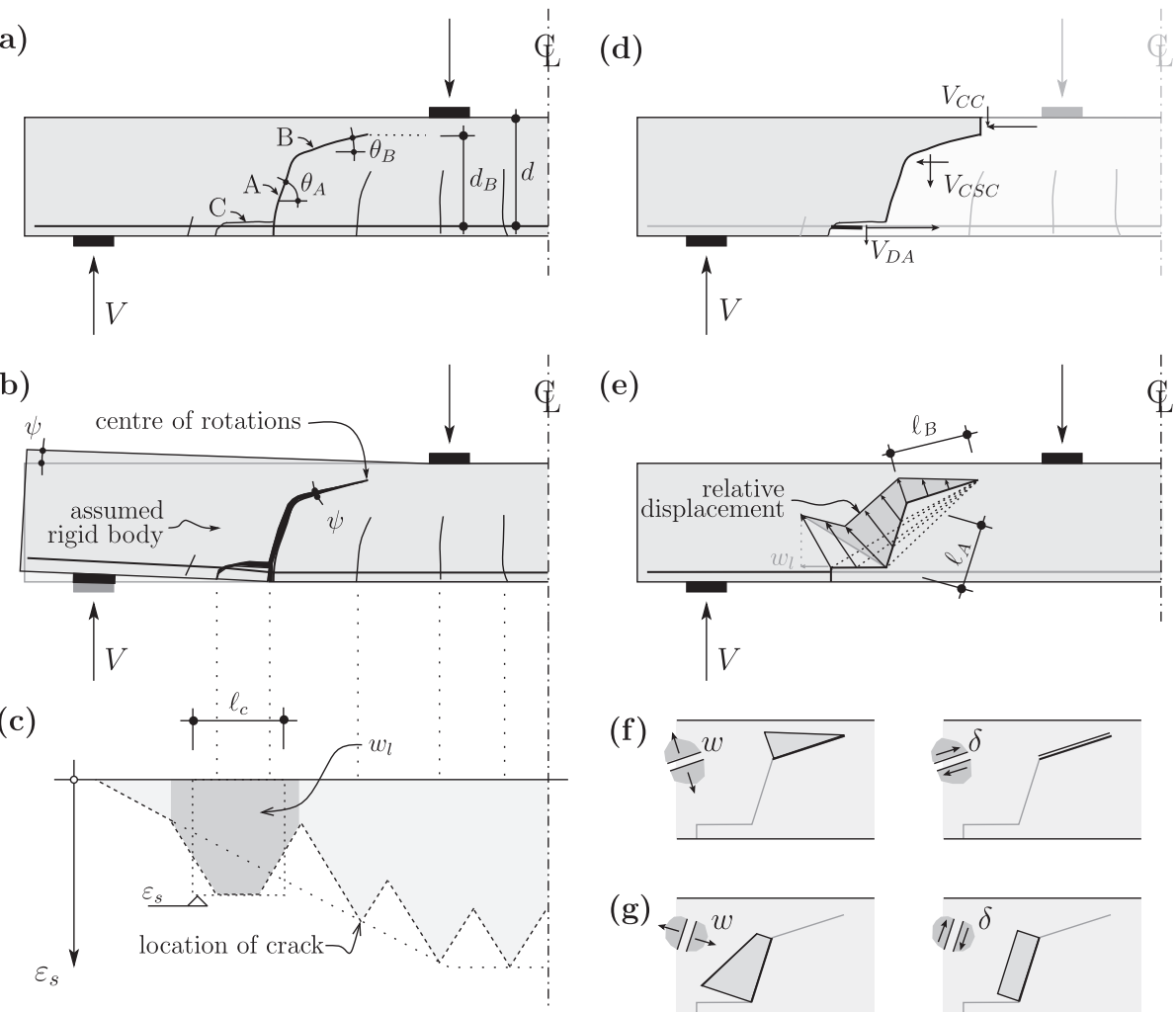

(e)



(f)

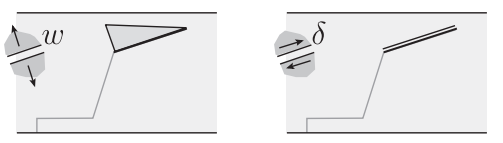

(g)

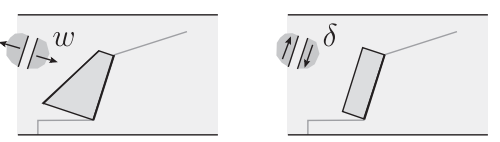

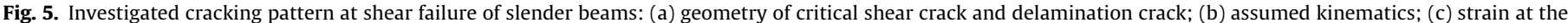

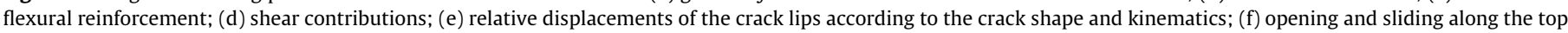
part of the critical shear crack; and (g) opening and sliding along the bottom part of the critical shear crack.


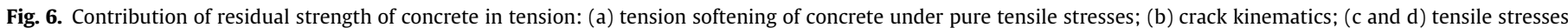

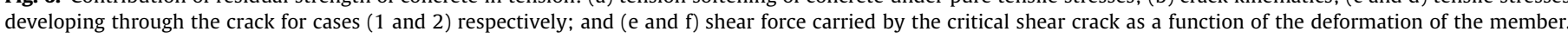

$w=\psi \cdot \eta$

Two regimes are potentially possible, refer to Fig. $6 \mathrm{c}$ and $\mathrm{d}$. These regimes have the following physical meaning: (1) cases when the normal stresses develop along the whole length of the investigated branch ( $w \leqslant w_{c r}$, corresponding to low crack openings), refer to
Fig. 6c; and (2) cases when the normal stresses develop only close to the tip of the crack $\left(w>w_{c r}\right.$ at the outermost part of the crack, corresponding to large crack openings). By introducing Eqs. (4) and (2) into Eq. (3) and solving the integral, the resulting shear force that can be transferred through the crack results: 
$V_{C S C, B}=\left\{\begin{array}{cc}b \cdot \ell_{B} \cdot f_{c t} \cdot \cos \theta_{B} \cdot\left(1-\frac{\psi \cdot \ell_{B}}{2 w_{c r}}\right) & 0 \leqslant \psi \leqslant \frac{w_{c r}}{\ell_{B}} \\ b \cdot \ell_{B} \cdot f_{c t} \cdot \cos \theta_{B} \cdot \frac{1}{2 \cdot \psi \cdot \ell_{B}} & \psi>\frac{w_{c r}}{\ell_{B}}\end{array}\right.$

The two regimes can be identified in Fig. 6e, where the shear force carried through the top part of the critical shear crack is expressed as a function of $\psi$. The first regime corresponds to a linear decay (while the normal stresses develop through the whole depth of the crack) and is followed by an hyperbola (when the normal stresses develop only for a given length of the crack). It can be noted that the larger the deformation of the member (associated to larger crack widths), the lower the shear strength that can be transferred through the critical shear crack.

Alternatively, Eq. (5) can also be formulated on the basis of other parameters that may be more convenient for design. For instance, this can be done in the following manner:

- The tensile strength can be related to the compressive strength of concrete. Usually, relationships of the type

$f_{c t}=k_{1} f_{c}^{\alpha}$

are used. According to Model Code 2010 [40], suitable values are $k_{1}=0.3$ and $\alpha=2 / 3$. Other authors relate the tensile strength of concrete to other powers of the compressive strength, generally varying between 0.5 [42] and 2/3.

- Parameter $w_{c r}$ can be related to the fracture energy $G_{F}$ for the proposed linear law as

$w_{c r}=\frac{2 G_{F}}{f_{c t}}$

The fracture energy is in turn significantly influenced by the compressive strength of concrete and by the maximum size of the aggregates $[40,41]$. Based on the results provided by Hilsdorf and Brameshuber [41], the following relationship can be used for calculating the value of the fracture energy of concrete:

$G_{F}[\mathrm{~N} / \mathrm{mm}]=0.002 \cdot\left(\frac{d_{g}+d_{g 0}}{d_{g 0}}\right)\left(f_{c}\right)^{0.7}$

where $d_{g}$ refers to the maximum aggregate size, $d_{g 0}$ to a reference aggregate size $(8 \mathrm{~mm})$ and $f_{c}$ is to be introduced in [MPa]. Accounting for $f_{c t}=0.3 f_{c}^{2 / 3}$, it results (assuming $f_{c}^{0.033} \approx 1$ ):

$w_{c r}=k_{2}\left(d_{g}+d_{g 0}\right)$

It can be noted that other approaches may estimate the fracture energy $G_{F}$ with different expressions, giving for instance less significance to the aggregate size and decreasing the value of the power applied to the concrete strength (refer for instance to [40]).

- The length $\ell_{B}$ can be assumed to be proportional to the distance between two cracks defining a concrete tooth (refer to Figs. 2 and 5a). This distance has been in its turn observed to be proportional to the effective depth of the member [43]. Thus, it can be assumed:

$\ell_{B} \propto d$

The effective depth of the critical shear crack $\left(d_{B}\right)$ can be assumed proportional to the effective depth of the member assuming a cracked flexural behaviour of the member [15]. If the length of the region contributing to the opening of the critical shear crack (named $\ell_{c}$ in Fig. $5 \mathrm{c}$ and including its delamination branch) is also assumed to be proportional to the effective depth of the member, the rotation $\psi$ of the critical shear crack can be related to a reference longitudinal strain of the member $\varepsilon$ (larger longitudinal strains in the member being associated to larger rotations [15]) according to Eq. (1): $\psi \propto \varepsilon$

With these assumptions, Eq. (5) can be rewritten as:

$\frac{V_{C S C, B}}{b \cdot d \cdot f_{c}^{\alpha}}=\left\{\begin{array}{cr}k_{\sigma} \cdot\left(1-\frac{\varepsilon \cdot d}{2 k_{\psi}\left(d_{g}+d_{g 0}\right)}\right) & 0 \leqslant \varepsilon \leqslant k_{\psi} \frac{d_{g}+d_{g 0}}{d} \\ \frac{k_{\sigma}}{2} \frac{k_{\psi} \cdot\left(d_{g}+d_{g 0}\right)}{\varepsilon \cdot d} & \varepsilon>k_{\psi} \frac{d_{g}+d_{g 0}}{d}\end{array}\right.$

where $k_{\sigma}$ and $k_{\psi}$ are constants depending on the material parameters and crack inclination $\theta_{B}$. This formula is plotted in Fig. $6 \mathrm{f}$, where the vertical axis is normalised by the factor $b \cdot d \cdot f_{c}^{\alpha}$.

The figure shows still the two regimes (linear and hyperbolic) and the decay on the shear strength for increasing deformation or sizes. It can thus be observed that both size and strain effects are naturally resulting from the physical phenomenon (reduction of the shear strength for increasing openings of the shear crack) without the need of accounting for any specific (or empirical) factor.

\subsection{Contribution of the bottom part of the critical shear crack}

With respect to the bottom part of the critical shear crack, both opening and sliding occur according to Fig. 5g. This implies a response in mixed mode I and II, that can be evaluated by means of aggregate interlock models (Fig. 3). In this case, an analytical integration of the contribution of aggregate interlock can also be performed with reference to the simplified laws shown in Fig. 7a (where both the slip and opening between the lips of the crack increase proportionally with the rotation $\psi$ ). These laws assume a linear decay on the shear and normal stresses that can be transferred through aggregate interlock, with a maximum stress transferred for perfect contact (no crack opening) and no stress transferred for a limit crack opening $\left(w_{l i}\right)$ where no contact between the crack develops for any relative slip:

$\tau=\left\{\begin{array}{cc}\tau_{0}\left(1-\frac{w}{w_{l i}}\right) & 0 \leqslant w \leqslant w_{l i} \\ 0 & w>w_{l i}\end{array}\right.$

$\sigma=\left\{\begin{array}{cc}\sigma_{0}\left(1-\frac{w}{w_{l i}}\right) & 0 \leqslant w \leqslant w_{l i} \\ 0 & w>w_{l i}\end{array}\right.$

More refined laws for the maximum aggregate interlock stress developed for a given crack opening can be derived from the rough crack model (proposing an hyperbolic [22] or square-root [23] decay with increasing crack opening instead of a linear one, but keeping the same governing parameters). The selected linear laws for aggregate interlock behaviour can be replaced, without loss of generality, by more realistic envelopes of aggregate interlock stresses calculated on the basis of the actual crack opening and slip (refer to dotted lines in Fig. 7a) which in turn affect the contact surface as well as the amount and distribution of sizes of aggregates) and by assuming a plastic strength in the concrete matrix (as for instance performed by Walraven [21]). These envelopes lead to an activation phase (where contact is not developed in all potential contact surfaces) prior to developing the plastic strength at the interface (refer to Fig. 7a). Integration of such laws requires typically using numerical procedures [17]. Due to this reason, the simplified laws will be used in the following, but the influence of the activation phase will be discussed with reference to the total amount of shear force that can be transferred through the critical shear crack.

By accounting for the crack shape and kinematics, the relative displacements between the lips of the cracks can be obtained (Fig. 7b). On the basis of such displacements and the aggregate interlock laws (Fig. 7a), the shear stresses at the critical shear crack 
(a)

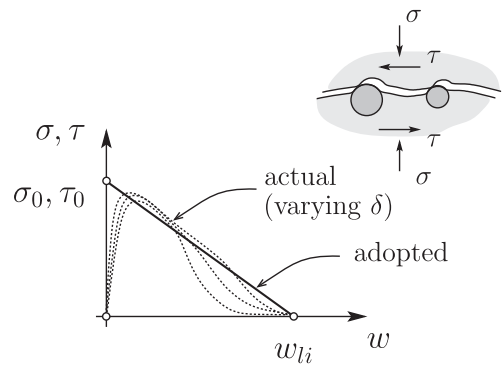

(b)

(e)


(c)

(d)

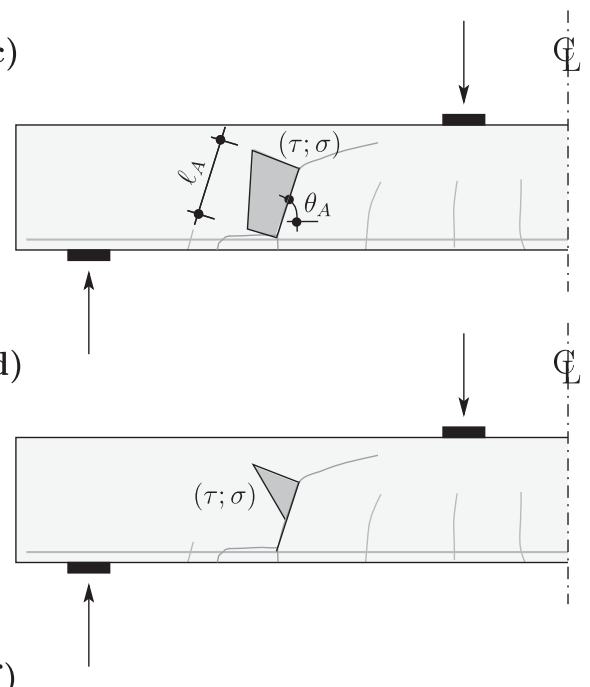

(f)

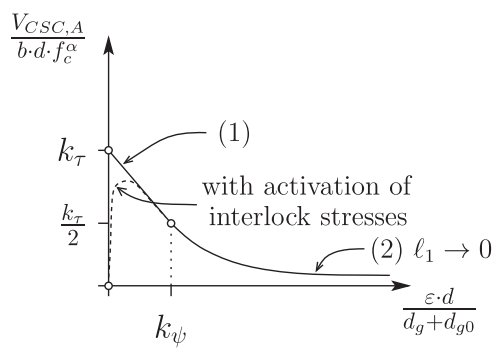

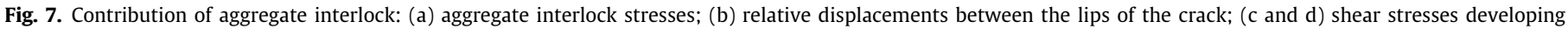
through the crack for cases ( 1 and 2 ) respectively; and (e and f) shear force carried by the critical shear crack as a function of the deformation of the member.

can be determined as shown in Fig. 7c and d. It can be noted that both shear and normal stresses result. It can thus be written:

$V_{\mathrm{CSC}, A}=\int_{\xi=\ell_{1}}^{\ell_{2}} \tau \cdot b \cdot \sin \theta_{A} d \xi-\int_{\xi=\ell_{1}}^{\ell_{2}} \sigma \cdot b \cdot \cos \theta_{A} d \xi$

where $\ell_{1}$ and $\ell_{2}$ refer to the integration limits that can be calculated on the basis on the geometry of the critical shear crack defined in Fig. 5 as:

$\ell_{1}=\ell_{B} \cos \left(\theta_{A}-\theta_{B}\right)$

$\ell_{2}=\ell_{1}+\ell_{A}$

It can be noted that, for slender member, cracks develop in a rather vertical manner. In addition, the normal stresses associated to aggregate interlock are normally significantly lower than the shear stresses [44] for realistic crack kinematics. Accounting for these two arguments, the term concerning the shear stresses can be considered as dominant. In the following, and for simplicity reasons, only this term will be considered, although the general integration could be performed reaching the same conclusions (the shear and normal stresses develop in affinity as a function of the crack width according to Fig. 7a):

$V_{C S C, A}=\kappa \cdot b \int_{\xi=\ell_{1}}^{\ell_{2}} \tau \cdot d \xi$

where the coefficient $\kappa$ accounts for the contribution of the normal stresses and the influence of the angle $\theta_{A}$. It can be noted that the actual value of the parameter $\tau_{0}$ depends on the crack kinematics (angle of the displacement vector with respect to the crack plane [44]). Although this angle varies along the crack, this variation is limited and will be neglected in the following for simplicity reasons (an integration accounting for this fact would not influence the results presented hereafter).

The integration of the aggregate interlock stresses leads in this case to three potential regimes: (1) cases where the shear stresses develop through the whole depth of the vertical part of the crack (Fig. 7c); (2) cases where the shear stresses develop only on the top region of the vertical part of the shear crack (Fig. 7d); and (3) cases where no shear stresses develop in the vertical branch of the critical shear crack (since the opening of the crack in the vertical branch exceeds the limit value $w_{l i}$. Integration of the shear stresses results thus in the following expression:

$V_{C S C, A}= \begin{cases}b \cdot \ell_{A} \cdot \tau_{0} \cdot \kappa\left(1-\frac{\psi \cdot\left(\ell_{1}+\ell_{2}\right)}{2 w_{l i}}\right) & 0 \leqslant \psi \leqslant \frac{w_{l i}}{\ell_{2}} \\ b \cdot \ell_{A} \cdot \tau_{0} \cdot \kappa \frac{1}{2}\left(1-\frac{\psi \cdot \ell_{1}}{w_{l i}}\right)\left(\frac{w_{l i}}{\psi \cdot \ell_{A}}-\frac{\ell_{1}}{\ell_{A}}\right) & \frac{w_{l i}}{\ell_{2}}<\psi \leqslant \frac{w_{l i}}{\ell_{1}} \\ 0 & \psi>\frac{w_{l i}}{\ell_{1}}\end{cases}$

where $\tau_{0}$ refers to the maximum shear stress that can be transferred through aggregate interlock (Fig. 7a) and $\psi$ to the rotation developed at the tip of the critical shear crack. It can be noted that for low values of $\ell_{1}\left(\ell_{1} \rightarrow 0\right)$, the regimes simplify to two and lead to a linear decay of the shear strength followed by an hyperbolic decay:

$V_{C S C, A}= \begin{cases}b \cdot \ell_{A} \cdot \tau_{0} \cdot \kappa\left(1-\frac{\psi \cdot \ell_{2}}{2 w_{l i}}\right) & 0 \leqslant \psi \leqslant \frac{w_{l i}}{\ell_{2}} \\ b \cdot \ell_{A} \cdot \tau_{0} \cdot \kappa \frac{1}{2} \frac{w_{l i}}{\psi \cdot \ell_{A}} & \psi>\frac{w_{l i}}{\ell_{2}}\end{cases}$

Eqs. (12) and (13) are plotted in Fig. 7e. For design purposes, these equations can be rewritten accounting for other physical parameters more suited for design: 
- The maximum shear stress is related to a number of parameters such as the cement paste strength, aggregate type, maximum size of aggregate and aggregate volume fractions. However, the governing parameter for normal strength aggregates, can be considered the cement paste strength (as the aggregate size decreases, the force transferred by each aggregate diminishes, but the total number of aggregates transferring shear increases, both effects compensating as can be observed from the aggregate interlock relationships of [22,23]). This term, according to Walraven's model [21] can be assumed as proportional to the power 0.56 of the compressive strength of concrete: $\tau_{0} \propto f_{c}^{0.56}$. Other authors (as the rough crack model [22,23]) assume a linear dependency of the maximum shear strength with respect to the compressive strength of concrete $\tau_{0} \propto f_{c}$. In the following, it will be assumed:

$\tau_{0} \propto f_{c}^{\alpha}$

where the exponent $\alpha$ varies potentially between 0.56 and 1.0 (similar values but not necessarily the same as those already discussed for the contribution of the top part of the critical shear crack)

- Parameter $w_{l i}$, referring to the crack opening leading to no contact between the lips of the crack for any value of the sliding, can be correlated to the maximum aggregate size and crack roughness. This is justified because half the maximum aggregate will lead to a no-contact situation for a crack developing in a planar surface (contact of the aggregates refers to the micro-roughness of the crack). However, concrete cracks are not perfectly planar and present a certain level of meso-roughness, Fig. 7a. The limit crack width is thus related to a reference dimension related to the sum of the micro- and meso-roughnesses:

$w_{l i} \propto d_{g}+d_{g 0}$

where $d_{g 0}$ refers to a reference size (not necessarily identical to that of the residual tensile strength).

- The length of the quasi-vertical cracked zone can be assumed proportional to the effective depth of the member $\left(\ell_{2} \propto d\right)$ if the crack extends up to the neutral axis [15].

- The rotation $\psi$ of the critical shear crack is, as previously, assumed proportional to a reference longitudinal strain of the member $\varepsilon$, thus $\psi \propto \varepsilon$.

In light of these assumptions, and considering the previous simplification of $\ell_{1} \rightarrow 0$ (the general Equations could also be applied without loss of generality) Eq. (13) can be rewritten as:

$$
\frac{V_{C S C, A}}{b \cdot d \cdot f_{c}^{\alpha}}= \begin{cases}k_{\tau} \cdot\left(1-\frac{\varepsilon \cdot d}{2 k_{\psi}\left(d_{g}+d_{g 0}\right)}\right) & 0 \leqslant \varepsilon \leqslant k_{\psi} \frac{d_{g}+d_{g 0}}{d} \\ \frac{k_{\tau}}{2} \frac{k_{\psi}\left(d_{g}+d_{g 0}\right)}{\varepsilon \cdot d} & \varepsilon>k_{\psi} \frac{d_{g}+d_{g 0}}{d}\end{cases}
$$

where $k_{\tau}$ and $k_{\psi}$ are constants depending on the material parameters (where $k_{\psi}$ does not necessarily have the same value as for Eq. (6)). The regimes are plotted in Fig. $7 f$. In addition, another curve (dotted line) is plotted accounting for the activation of the aggregate interlock stresses (as previously referred, see also Fig. 7a). It is noticeable that Eqs. (6) and (14) have the same shape and mechanical parameters implied, despite their different physical and kinematical origins. The shear strength can be normalized by the product of the width, effective depth of the member and a power of the compressive strength of concrete. The opening of the critical shear crack can in turn be related to the product of a longitudinal reference strain times the effective depth of the member. Both expressions lead to a decay on the shear strength that can be transferred through the critical shear crack for an increasing opening of the critical shear crack. In addition, both predict the same influence of size and strain (by means of the product $\varepsilon \cdot d$ ) on the shear strength.

\subsection{Contribution of dowelling action}

Dowelling action can also be mobilized according to the considered crack geometry and kinematics, as the flexural reinforcement follows a transversal displacement in addition to the longitudinal one, refer to Fig. 5e. In order to activate dowelling action in the flexural reinforcement, it is necessary that tensile stresses develop in the concrete (Fig. 2c). As shown in Fig. 8a, the equilibrium of the shear force in the reinforcement requires the development of vertical tensile stresses, potentially originating a delamination crack. Despite the development of this delamination crack, the dowelling action can still occur, as the tensile stresses develop again at the tip of the delamination crack (Fig. 8b). This leads in fact to a plastic behaviour of the dowelling strength that has been confirmed experimentally, refer for instance to the works of Baumann and Rüsch [25] shown in Fig. 8d (specimens whose inner wedge was separated at casting by means of two plastic layers to measure the dowelling action of the reinforcement). It can be noted in Fig. 8d that shear transfer by dowelling of the flexural reinforcement was activated for very low values of transverse displacement and the force was roughly constant thereafter, giving rise to a delamination crack of the longitudinal reinforcement as that presented in Fig. $2 \mathrm{~b}$.

The capacity of dowelling action to transfer shear forces is limited in slender members if no transverse reinforcement is available [25-28]. Yet, its value is not necessary negligible in all cases (refer to Fig. 8d) and can be expressed in a general manner as [31]:

$V_{D A}=n \cdot f_{c t, e f} \cdot b_{e f} \cdot \ell_{e f}$

where $n$ refers to the number of bars, $f_{c t, e f}$ to the effective tensile strength of concrete, $b_{e f}$ to the effective width in tension per bar (Fig. 8c) and $\ell_{e f}$ to the effective concrete length in tension (Fig. 8a). According to [31]:

- $b_{e f}$ can be estimated as the minimum of the values $\left(s_{b}-d_{b} ; 6 d_{b}\right.$; $4 c_{b}$ ), where $s_{b}$ refers to the spacing between the bars, $d_{b}$ to their diameter and $c_{b}$ to their cover.

$-\ell_{\text {ef }}$ can be estimated as two times the bar diameter $\left(\ell_{\text {ef }}=2 d_{b}\right)$.

With respect to the effective tensile strength, it should be noted that its value is strongly influenced by the state of longitudinal strains in the flexural reinforcement. This evidence has been experimentally demonstrated in [45], refer to Fig. 8e. It is justified by the fact that reinforcement strains in cracked concrete are associated to bond stresses between the concrete and the steel. These bond stresses require the development of transversal tension rings (according to Tepfers [46]) which limit the capacity of the concrete cover to withstand any other transverse actions (as dowelling forces). According to [45], the effective tensile strength can be estimated as a function of the deformations of the flexural reinforcement according to the following expression:

$f_{c t, e f}=k_{b}(\varepsilon) \cdot f_{c t}$

where the reduction factor $\left(k_{b}\right)$ follows a decay for increasing strains at the flexural reinforcement as shown in Fig. 8e [45]. It can be noted that if Eq. (16) is introduced into Eq. (15) and the strength is normalized, it results:

$\frac{V_{D A}}{f_{c t} \cdot b \cdot d}=\frac{b_{e f}}{s_{b}} \frac{\ell_{e f}}{d} k_{b}(\varepsilon)=\frac{b_{e f}}{s_{b}} \frac{2 d_{b}}{d} k_{b}(\varepsilon)$

The strength depends thus on the level of deformation of the specimen (strain effect) and on the ratios $b_{e f} / s_{b}$ and $d_{b} / d$. It should be noted that, in practical applications, the bar spacing $\left(s_{b}\right)$ in slabs 
(a)

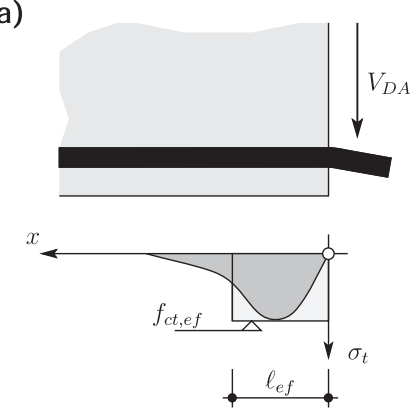

(b)

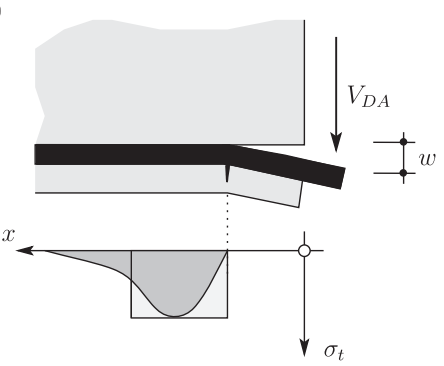

(d)



(c)

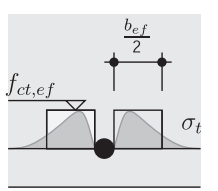

(e)

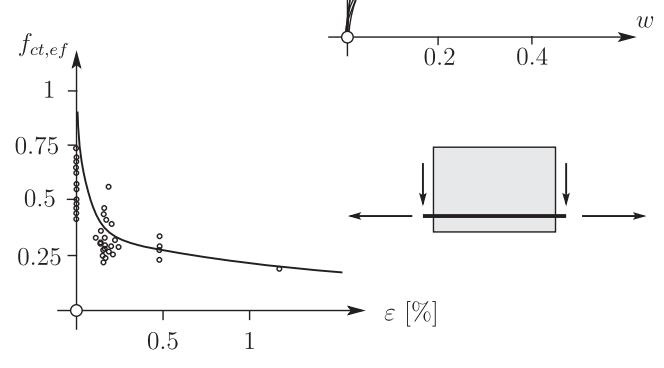



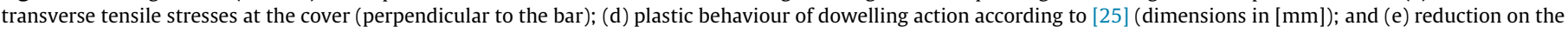
effective tensile strength as a function of the longitudinal strains in the bar (experimental data according to [45]).

is normally kept constant or almost constant. Thus, for the same amount of flexural reinforcement ratio, $d_{b}$ has to vary according to the square-root of the effective depth of the member. The influence of size will thus be different depending on whether $b_{e f}$ is governed by the condition $6 d_{b}$ or $s_{b}-d_{b} \approx s_{b}$. In a general manner, this dependency can then be written as:

$\frac{V_{D A}}{f_{c}^{\alpha} \cdot b \cdot d} \approx \frac{k_{d}}{d^{\beta}} \cdot k_{b}(\varepsilon)$

where $k_{d}$ and $\beta$ are constants depending on the geometrical and mechanical parameters and $f_{c t}$ has been approximated as a power of $f_{c}$ as previously justified for the contribution of the residual tensile strength of concrete. It can be noted that Eq. (18) includes an explicit dependency on the strain and on the size of the member. Yet, both phenomena are still related as it will be explained later (larger sizes are associated to lower strains).

\subsection{Contribution of compression chord/arching action}

Other than the residual tensile strength of concrete, aggregate interlock and dowel action, shear can be transferred by means of the inclination of the compression chord $\left(V_{C C}\right.$, refer to Figs. 2a,f and $5 d$ ). This action is governing for short-span beams although its influence is more limited for slender members [36].

In the case of slender members, shear can be transferred at the location of the cracks by means of the cantilever action (Fig. 2a), where the shear force is carried by the inclination of the compression chord. This action is however disabled as the critical shear crack propagates in a quasi-horizontal manner (Fig. 9a) leading to the kinematics shown in Fig. 9b on the basis of a simplified critical shear crack shape. In this situation, a contribution of the compression chord is still possible provided that an inclined compression strut develops. The angle of the compression strut ( $\beta_{C C}$ in Fig. 9c) is governing for the amount of shear force that can be transferred by the compression chord and this angle depends much on the height and location of the critical shear crack (point A in Fig. 9a and b). Developing a full-arching action (Fig. 2e, characterized by a theoretical direct strut carrying the total shear force and developing between the loading plate and the support) is possible for short-span beams but it is however not possible for slender members since the inclined strut would be intercepted by the critical shear crack (Fig. 9c), refer to Fig. 4. For slender members, the inclination of the compression chord is thus flatter than that corresponding to the full arching action ( $\beta_{A A}$ in Fig. $\left.9 c\right)$. This results from the assumption that the beam shear transfer actions in the region between the critical shear crack and the load are neglected (yet they are still active in the region between the support and the critical shear crack to deviate the inclined strut of the compression chord). As a consequence, the remaining shear force is carried by the previously investigated shear-carrying actions, mostly by means of a strut developing at an angle $\beta_{C S C}$ corresponding to aggregate interlock and concrete contribution in tension if dowel action is neglected, refer to Fig. 9c. On the basis of the force diagram (Fig. 9c) it can be seen that, for activating the arching action, both shear contributions $\left(V_{C C}\right.$ and $V_{C S C}$ ) are related by geometric conditions:

$V_{C C}=V_{C S C} \cdot \frac{\cot \beta_{A A}-\cot \beta_{C S C}}{\cot \beta_{C C}-\cot \beta_{A A}}$

where in Eq. (19), the value of $\beta_{A A}$ is constant (as $\cot \beta_{A A}$ refers to the slenderness ratio $a / z$ ). The value of $\beta_{C C}$ is also constant as it is determined by the location of point $A$ of the crack. The value of $\beta_{C S C}$ can also be assumed as roughly constant since the resultant of 
(a)

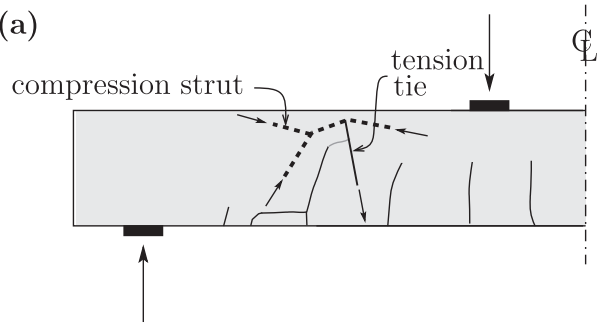

(b)

(c)



Fig. 9. Analysis of the compression chord for slender members: (a) flexural cracking pattern and cantilever action; (b) development of the horizontal branch of the critical shear crack; and (c) inclined compression strut.

aggregate interlock stresses is located close to point A of the crack (refer to the distribution of shear stresses in Fig. 7c). As a consequence, failures associated to such cracking pattern implies that both shear transfer actions $\left(V_{C C}\right.$ and $\left.V_{C S C}\right)$ are roughly proportional and the contribution of the compression chord will be governed by the same parameters controlling the shear carried through the critical shear crack (Eqs. (6) and (14)). It can be noted that this approach assumes that failure results from loss of resistance in the critical shear crack and that the proportion of load taken by the inclined compression chord is determined by the geometry and the position of the critical shear crack.

\section{The Critical Shear Crack Theory as a mechanical model for shear design}

The Critical Shear Crack Theory (CSCT) is a theory whose fundamentals were first presented in 1991 [47] and that can be applied for shear design of one- and two-way slabs $[15,48,49,16]$ with and without transverse reinforcement or fibres [50-52]. A design formulation based on this theory has recently been incorporated in fib Model Code 2010 [40,53] with reference to the punching shear strength of two-way slabs. The theory states, consistently to what has been presented previously, that the shear strength of reinforced concrete members without transverse reinforcement depends on the opening and roughness of a critical shear crack transferring shear [15].

In the CSCT, the width of the critical shear crack is estimated proportional to a reference longitudinal strain (Fig. 10a-c) times the effective depth of the member [15] $(w \propto \varepsilon \cdot d)$, which is in agreement to the considerations presented in this paper. On that basis, Muttoni and Fernández Ruiz [15] proposed the following equation for the failure criterion (refer to Fig. 10d):
$V_{C}=\frac{b d \sqrt{f_{c}}}{3} \frac{1}{1+120 \frac{\varepsilon \cdot d}{d_{g 0}+d_{g}}}[\mathrm{MPa}, \mathrm{mm}]$

By comparing Eq. (20) to the previous equations derived for the residual tensile strength and aggregate interlock contributions (Eqs. (6) and (14)), it can be noted that they are similar, with the same parameters governing the shear strength and showing a similar shape. Also the limit cases $(\varepsilon \rightarrow 0$ and $\varepsilon \rightarrow \infty)$ are correctly reproduced for each governing regime. This holds also true for the contribution of the compression chord (Eq. (19)) as previously explained. With respect to the dowelling action (whose contribution can be considered as more limited), it is also dependent on the same parameters (strain and size) and presents a similar dependency on them, refer to Eq. (18), yet it is also influenced by the detailing rules considered (spacing, concrete cover, bar diameter).

A comparison of the failure criterion of the CSCT and the contribution of the shear transfer actions is qualitatively shown in Fig. 10e (the amount of force carried by each shear-transfer depends on the actual crack shape and kinematics [17]). The power of the concrete compressive strength is assumed by the CSCT to be 0.5 (within the previously determined range), and a reference size of $16 \mathrm{~mm}$ is considered for parameter $d_{g 0}$ (yet consistent to those previously observed). The previous comparison of the selected shape of the CSCT (Eq. (13)) and the analytically-derived formulas for the various shear-carrying actions validate the proposed shape as well as its generality independently of the governing shear-carrying actions. For design purposes, Eq. (20) has nevertheless the advantage that it is defined by only one analytical curve (which greatly simplifies its use) yet accounting for the governing parameters, limit cases and influences of the various implied phenomena derived from the mechanical models previously presented.

\section{Size-effect law consistency of the CSCT}

One interesting aspect of the CSCT is that it accounts directly for the size and strain effects. Whereas in many shear approaches both effect are explicitly introduced by means of strength correction factors (empirical in many cases [3]), the CSCT considers them naturally on the basis of its physical assumptions (without the need of adding any correction factor). It can be noted that in the formulation of Eq. (20) both phenomena (influence of size and strain) are related. Specimens of larger sizes, for instance, will fail at lower levels of unitary shear forces (due to size effect) if the reinforcement ratio remains constant, thus being subjected to lower levels of deformation. In order to perform a consistent investigation of the size effect law predicted by the CSCT, such dependency should be suitably addressed. This can be done for instance by replacing the reference strain (Fig. 10b) as a function of the size and acting shear force of the member. According to a cracked sectional analysis [15], refer to Fig. 10a-c, this reference strain can be estimated as:

$\varepsilon=\frac{M}{d \cdot b \cdot \rho \cdot E_{s} \cdot(d-c / 3)} \frac{0.6 d-c}{d-c}$

where $M$ refers to the acting bending moment at the control section and $c$ refers to the depth of the compression zone [15]:

$c=d \cdot \rho \cdot \frac{E_{s}}{E_{c}}\left(\sqrt{1+\frac{2 E_{c}}{\rho \cdot E_{s}}}-1\right)$

It can be noted that the bending moment $M$ is related to the shear force. For instance, assuming a simply supported beam, where the location of the nominal control section is set at $d / 2$ of the mid-span according Fig. 10a (the demonstration can be generalised to other cases), the shear strength results: 
(a)

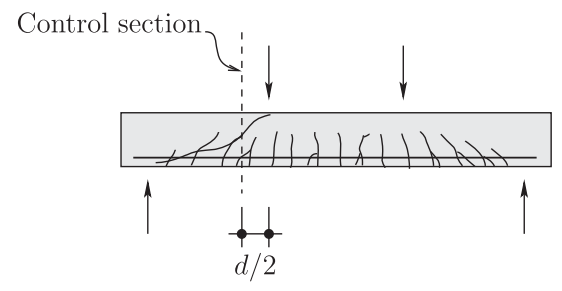

(d)

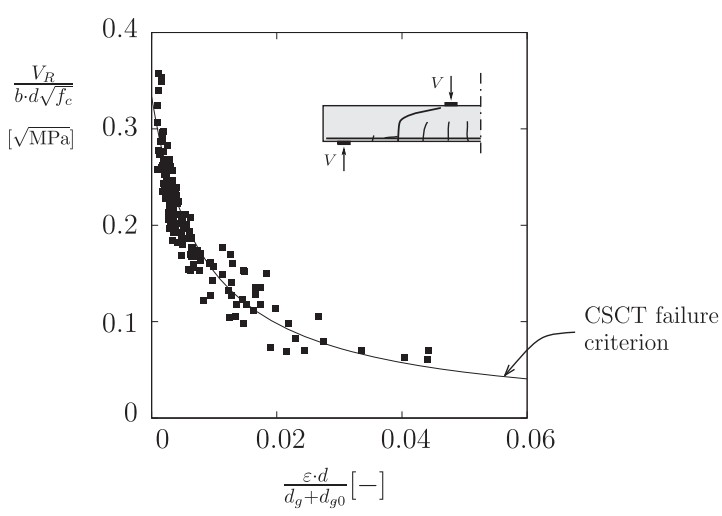

(b)

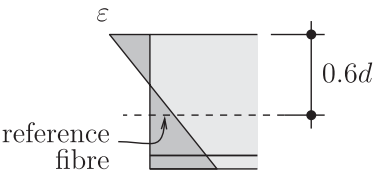

(e)

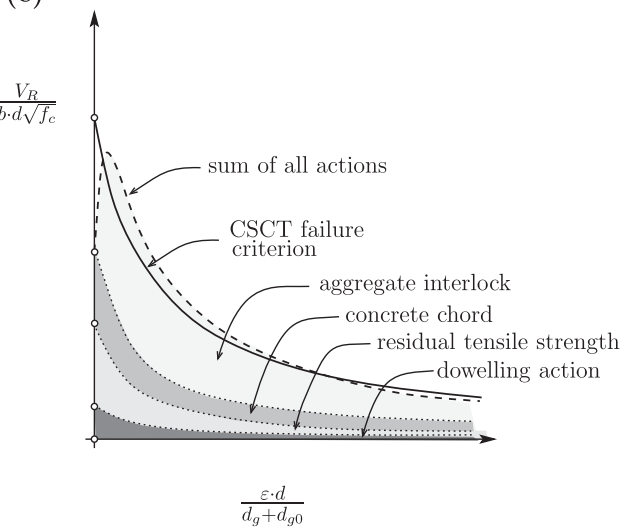

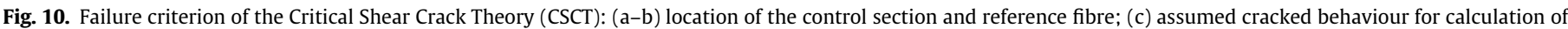

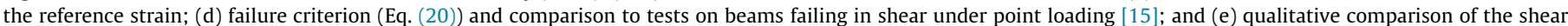
transfer actions contributions and the CSCT failure criterion.

(a)

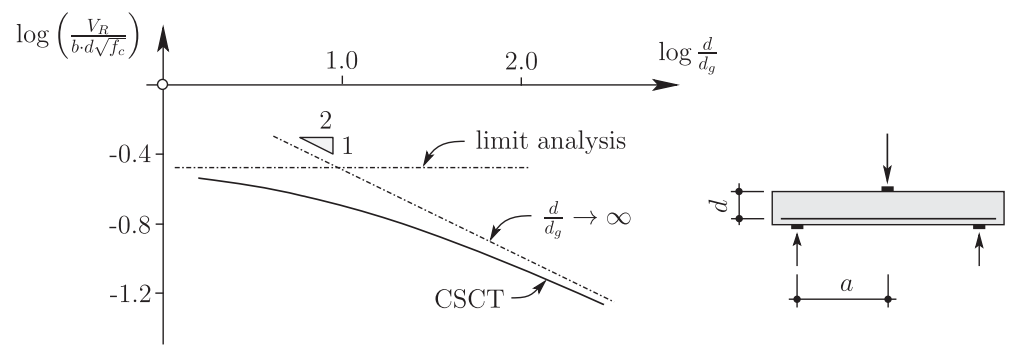

(b)

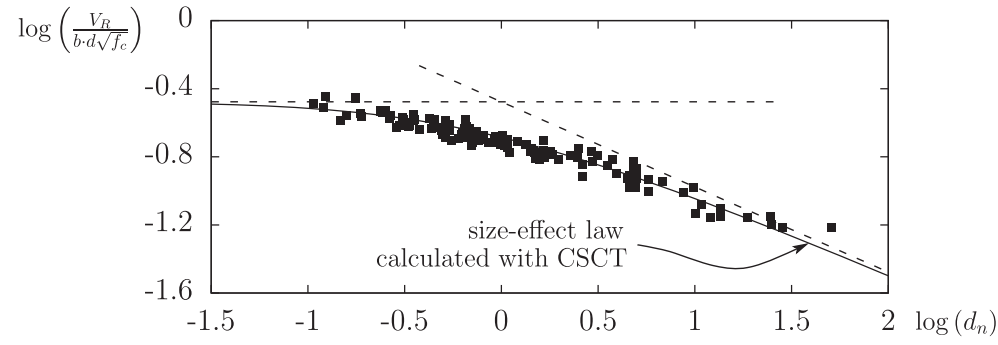

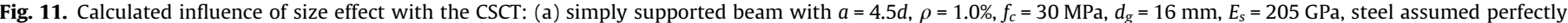
elastic (ratio $\alpha /\left(\beta \cdot d_{g}\right)=10$ ); and (b) comparison of the size effect law predicted by the CSCT to the test dataset given in [15].

$V_{R} \frac{3}{\underbrace{b d \sqrt{f_{c}}}_{\alpha / d}} \cdot(1+V_{R} \underbrace{\frac{120 \cdot d}{d_{g 0}+d_{g}} \frac{(a-d / 2)}{d \cdot b \cdot \rho \cdot E_{s} \cdot(d-c / 3)} \frac{0.6 d-c}{d-c}}_{\beta})=1$

where the parameters $\alpha$ and $\beta$ are independent of $d$ (since the shear span $a$ is proportional to $d$ in order to keep scaled geometries, $c$ is proportional to $d$ according to Eq. (22) and $d_{g}$ is kept constant). Thus:
$V_{R}=\frac{-1+\sqrt{1+\frac{4 \beta}{\alpha} d}}{2 \beta}$

If the strength is normalized by $b d \sqrt{f_{c}}=3 d / \alpha$, it results:

$\frac{V_{R}}{b d \sqrt{f_{c}}}=\frac{-1+\sqrt{1+4 \frac{\beta d}{\alpha}}}{6 \frac{\beta d}{\alpha}}$ 
Thus, for very large sizes $(d \rightarrow \infty)$ the expression can be simplified as:

$$
\frac{V_{R}}{b d \sqrt{f_{c}}}=\frac{1}{3} \sqrt{\frac{\alpha}{\beta \cdot d}}
$$

This Equation shows that, for very large sizes, the size effect depends on $d^{-0.5}$, in agreement to the LEFM [9]. This leads, in double logarithmic scale, to a slope $-1 / 2$ with respect to the influence of $d$ for these cases:

$\log \left(\frac{V_{R}}{b d \sqrt{f_{c}}}\right)=\log \left(\frac{1}{3} \sqrt{\frac{\alpha}{\beta}}\right)-\frac{1}{2} \log (d)$

Fig. 11a shows for instance a calculation of the influence of size for a typical case corresponding to a simply supported beam with a ratio $\alpha /\left(\beta \cdot d_{g}\right)=10 \quad\left(a=4.5 d, \rho=1.0 \%, f_{c}=30 \mathrm{MPa}, \quad d_{g}=16 \mathrm{~mm}\right.$, $E_{s}=205 \mathrm{GPa}$; steel is assumed to behave elastically). The CSCT is observed to consistently reproduce the limit behaviours predicted by the size-effect law [9] as well as to exhibit a smooth transition between them. It can be additionally noted that Eq. (25) can be rewritten in terms of the parameter $d_{n}=\beta d / \alpha$ as:

$\frac{V_{R}}{b d \sqrt{f_{c}}}=\frac{-1+\sqrt{1+4 d_{n}}}{6 d_{n}}$

This latter Equation describes in fact the size effect law predicted by the CSCT, which is compared in Fig. 11b to the same test data of Fig. 10d [15] (in double-logarithmic scale). The results show again a suitable prediction of the size effect and its limit behaviours. It can further be noted that the experiments (many of them corresponding to realistic sizes and mechanical properties for practical applications) are not necessarily governed by the yield criterion or the LEFM. This may also be considered as an additional argument supporting the differences that may be found in the governing shear-transfer actions for a given member [17].

As shown in Fig. 11b, size effect exhibits a significant influence on the shear strength of members without transverse reinforcement. Despite this fact, it can be noted that current codes of practice do not always account for its influence (as ACI 318-11 [2]) or may propose empirical expressions calibrated on the basis of limited dataset leading to inconsistent results (for instance, the size effect factor of Eurocode 2 [3], which predicts no influence of size effect for very large sizes). With this respect, a consistent treatment on a physical basis of size and strain effects is thus considered as a need for future design codes.

\section{Conclusions}

Various potential shear-transfer actions can develop in reinforced members cracked in bending (aggregate interlocking, residual tensile strength of concrete, dowelling action and inclination of compression chord). This paper investigates on the response of reinforced concrete beams with rectangular cross-section and on the governing parameters of shear strength with special reference to size and strain effects. Its main conclusions are listed below:

1. Aggregate interlocking and the residual tensile strength of concrete develop at the critical shear crack due to its shape and associated kinematics. The strength exhibited by both action decays for increasing openings of the critical shear crack, which occurs for increasing sizes and strains.

2. The dowelling action exhibits a more limited contribution for slender members, yet not necessary negligible. It is affected by a strain effect and also by a size effect depending on the detailing rules of the reinforcement (mainly on the ratio between the bar diameter and the effective depth of the member).
3. Arching action is potentially significant for beams with short shear span-to-effective depth ratios. For slender members, its contribution decreases due to the presence of the critical shear crack as the presence of this crack reduces the inclination of the compression chord. Its response is influenced by the same parameters as the residual tensile strength and aggregate interlock actions.

4. On the basis of the integration of the stresses developed in concrete for mechanical models of slender members simulating aggregate interlocking, residual tensile strength of concrete, dowelling action and the inclined compression chord, it can be observed that all shear-transfer actions depend in fact on the same physical parameters (concrete compressive strength, effective depth and width of the member, longitudinal strains or rotation and maximum aggregate size). Also, all lead to a similar shape decay on the shear stress that can be transferred through the critical shear crack for increasing openings of the critical shear crack.

5. The approach, hypotheses and failure criterion of the Critical Shear Crack Theory (CSCT) is shown to be consistent with the previous aspects. The failure criterion proposed in this theory for slender one-way slabs and beams suitably reproduces the shape and parameters observed for activation of the aggregate interlock, residual tensile strength of concrete, dowelling action and arching action.

6. The influences of size and strain on the shear strength of a member can be suitably reproduced by means of the CSCT. Both phenomena are yet coupled, as larger sizes are associated to lower levels of deformation. In this paper, it is also proven the consistency of the CSCT to the size-effect law predicted by Bažant et al., reproducing a smooth transition between a strength or yield criterion (without size effect, for small size specimens) to the behaviour predicted by Linear Elastic Fracture Mechanics (for specimens with very large sizes).

\section{References}

[1] ASCE-ACI Committee 445 on Shear and Torsion. Recent approaches to shear design of structural concrete. ASCE, J Struct Eng 1998;124(12):1375-417.

[2] ACI Committee 318. 318-11: Building code requirements for structural concrete and commentary. ACI; 2011. p. 503.

[3] CEN European Committee for Standardization. Eurocode 2. Design of concrete structures - general rules and rules for buildings. EN 1992-1-1, Brussels, Belgium; 2004. p. 225.

[4] Zararis PD. Shear strength and minimum shear reinforcement of reinforced concrete slender beams. ACI Struct J 2003;100(2):203-14.

[5] Vecchio FJ, Collins MP. The modified compression-field theory for reinforced concrete elements subjected to shear. ACI J 1986;83(2):219-31.

[6] Bentz EC, Vecchio FJ, Collins MP. Simplified modified compression field theory for calculating shear strength of reinforced concrete elements. ACI Struct J 2006;103(4):614-24.

[7] Yang Y. Shear behaviour of reinforced concrete members without shear reinforcement, a new look at an old problem. PhD thesis, Delft University of Technology, Delft, Netherlands; 2014. p. 344.

[8] Casanova P, Rossi P. Analysis and design of steel fiber reinforced concrete beams. ACI Struct J 1997;94(5):595-602.

[9] Bažant ZP, Kim J-K. Size effect in shear failure of longitudinally reinforced beams. ACI J Proc 1984;81(5):456-68.

[10] Bažant ZP, Sun H-H. Size effect in diagonal shear failure: influence of aggregate size and stirrups. ACI Mater J 1987;84(4):259-72.

[11] Zhang J-P. Diagonal cracking and shear strength of reinforced concrete beams. Mag Concr Res 1997;49(178):55-65.

[12] Fisker J. Shear capacity of reinforced concrete beams without shear reinforcement. PhD thesis, Aarhus University, Aarhus, Denmark; 2014. p. 155.

[13] Tue NV, Theiler W, Tung ND. Shear behaviour of bended members without transverse reinforcement (in German: Schubverhalten von Biegebauteilen ohne Querkraftbewehrung). Beton- Stahlbetonbau 2014;109(10):666-77.

[14] Marí A, Bairán J, Cladera A, Oller E, Ribas C. Shear-flexural strength mechanical model for the design and assessment of reinforced concrete beams. In: Structure and infrastructure engineering: maintenance, management, lifecycle design and performance. Taylor \& Francis Online; 2014. p. 21.

[15] Muttoni A, Fernández Ruiz M. Shear strength of members without transverse reinforcement as function of critical shear crack width. ACI Struct J 2008;105(2):163-72. Farmington Hills, USA. 
[16] Muttoni A. Punching shear strength of reinforced concrete slabs without transverse reinforcement. ACI Struct J 2008;105(4):440-50. USA.

[17] Campana S, Fernández Ruiz M, Anastasi A, Muttoni A. Analysis of sheartransfer actions on one-way RC members based on measured cracking pattern and failure kinematics. Mag Concr Res 2013;56(6):386-404. UK.

[18] Kani GNJ. The riddle of shear failure and its solution. ACI J Proc 1964;61(4):441-68. USA.

[19] Fenwick RC, Paulay T. Mechanisms of shear resistance of concrete beams. J Struct Div, ASCE 1968;94(10):2325-50.

[20] Taylor HPJ. Investigation of the forces carried across cracks in reinforced concrete beams in shear by interlock of aggregate. Technical Report no. 42. London, UK: Cement and Concrete Association; 1970. p. 77.

[21] Walraven JC. Fundamental analysis of aggregate interlock. ASCE J Struct Eng $1981 ; 107(11): 2245-70$.

[22] Bažant ZP, Gambarova PG. Rough crack models in reinforced concrete. ASCE-J Struct Eng 1980;106(4):819-42.

[23] Gambarova PG, Karakoç C. A new approach to the analysis of the confinement role in regularly cracking concrete elements. In: Trans. 7th struct mech in reactor tech, vol. H; 1983. p. 251-61.

[24] Dei Poli S, Gambarova P, Karakoç C. Aggregate interlock role in RC thin-webbed beams in shear. J Struct Eng, ASCE 1987;113(1):1-19.

[25] Baumann T, Rüsch H. Tests on dowelling action of flexural reinforcement of reinforced concrete beams (in German: Versuche zum studium der Verdübelungswirkung der Biegezugbewehrung eines Stahlbetonbalkens). Deutscher Ausscuss für Stahlbeton, vol. 210. Berlin, Germany: Wilhelm Ernst \& Sohn; 1970. p. 42-83.

[26] Dei Poli S, Di Prisco M, Gambarova P. Cover and stirrup effects on the shear response of dowel bar embedded in concrete. ACI Struct J 1993;90(4):441-50. USA.

[27] Krefeld W, Thurston CW. Contribution of longitudinal steel to shear resistance of reinforced concrete beams. ACI J 1966;63(3):325-44.

[28] Chana PS. Investigation of the mechanism of shear failure of reinforced concrete beams. Mag Concr Res 1987;39(141):196-204. UK.

[29] Jelić I, Pavlović MN, Kotsovos MD. A study of dowel action in reinforced concrete beams. Mag Concr Res 1999;2(2):131-41.

[30] Regan PE. Shear in reinforced concrete - an analytical study, Technical Note 46, London, Construction Industry Research \& Information Association (CIRIA), London; 1971. p. 199.

[31] Fernández Ruiz M, Mirzaei Y, Muttoni A. Post-punching behavior of flat slabs. ACI Struct J 2013;110(5):801-12.

[32] Hillerborg A. Analysis of a single crack. In: Wittmann FH, editor. Fracture mechanics of concrete. Amsterdam, Netherlands: Elsevier; 1983. p. 223-49.

[33] Hordijk DA. Tensile and tensile fatigue behaviour of concrete, experiments, modelling and analyses. Heron 1992:37(1):3-79.

[34] Drucker DC. On Structural concrete and the theorems of limit analysis, Publications, International Association for Bridge and Structural Engineering, vol. 21. Zürich, Switzerland; 1961. p. 49-59.

[35] Leonhardt F, Walther R. Shear tests in single span reinforced concrete beams with and without shear reinforcement (in German: Schubversuche an einfeldrigen Stahlbetonbalken mit und ohne Schubbewehrung), Deutscher Ausschuss für Stahlbeton 1962;151:83.

[36] Sagaseta J, Vollum RL. Shear design of short-span beams. Mag Concr Res 2010;62(4):267-82.

37] Fernández Ruiz M, Campana S, Muttoni A. Discussion of paper Influence of flexural reinforcement on shear strength of prestressed concrete beams' by E.I. Saquan, R.J. Frosch. ACI Struct J 2009;106(6):907-8. Farmington Hills, USA.

[38] Zhang N, Tan K-H. Size-effect in RC beams: experimental verification and STM verification. Eng Struct 2007;29(12):3241-54.

[39] Sagaseta J, Vollum RL. Influence of beam cross-section, loading arrangement and aggregate type on shear strength. Mag Concr Res 2011;63(2):139-55.

[40] Fédération Internationale du Béton (fib), Model Code 2010 - final draft, vols. and 2, fédération internationale du béton, Bulletins 65 and 66, Lausanne, Switzerland; 2012. p. 350 and p. 370.

[41] Hilsdorf HK, Brameshuber W. Code-type formulation of fracture mechanics concepts for concrete. International journal of fracture, vol. 51. The Netherlands: Kluwer Academic Publishers; 1991. p. 61-72.

[42] ACI. 435R-95 Control of deflection in concrete structures. ACI; 2003. p. 77.

[43] Collins MP, Mitchell D, Adebar P, Vecchio F. A General shear design method. ACI Struct J 1996;93(5):36-45.

[44] Jacobsen JS, Poulsen PN, Olesen JF. Characterization of mixed mode crack opening in concrete. Mater Struct 2012;45:107-22.

[45] Fernández Ruiz M, Plumey S, Muttoni A. Interaction between bond and deviation forces in spalling failures of arch-shaped members without transverse reinforcement. Am Concr Inst Struct J 2010;107(3):346-54.

[46] Tepfers R. A theory of bond applied to overlapped tensile reinforcement splices for deformed bars, Publication 73:2. Göteborg, Sweden: Chalmers University of Technology; 1973. p. 328

[47] Muttoni A, Schwartz J. Behaviour of beams and punching in slabs without shear reinforcement, IABSE Colloquium, vol. 62. Zurich, Switzerland; 1991. p. 703-8.

[48] Pérez Caldentey A, Padilla P, Muttoni A, Fernández Ruiz M. Effect of load distribution and variable depth on shear resistance of slender beams without stirrups. ACI Struct J 2012;109:595-603. USA.

[49] Vaz Rodrigues R, Muttoni A, Fernández Ruiz M. Influence of shear on rotation capacity of reinforced concrete members without shear reinforcement. AC Struct J 2010;107(5):516-25. Reston, USA.

[50] Fernández Ruiz M, Muttoni A. Applications of the critical shear crack theory to punching of $\mathrm{R} / \mathrm{C}$ slabs with transverse reinforcement. ACI Struct 2009;106(4):485-94. Farmington Hills, USA.

[51] Lips S, Fernández Ruiz M, Muttoni A. Experimental investigation on punching strength and deformation capacity of shear-reinforced slabs. ACI Struct J 2012;109:889-900. USA.

[52] Maya Duque LF, Fernández Ruiz M, Muttoni A, Foster SJ. Punching shear strength of steel fibre reinforced concrete slabs. Eng Struct 2012;40:93-4. UK.

[53] Muttoni A, Fernández Ruiz M, Bentz E, Foster SJ, Sigrist V. Background to the model code 2010 shear provisions - Part II punching shear. Struct Concr 2013;14(3):195-203. Ernst \& Sohn, Germany. 